\title{
Equivalent analgesic effectiveness between perineural and intravenous dexamethasone as adjuvants for peripheral nerve blockade: a systematic review and meta-analysis Équivalence de l'efficacité analgésique entre la dexaméthasone administrée par voie périnerveuse $v s$ intraveineuse en tant qu'adjuvant à un bloc du nerf périphérique : revue systématique et méta-analyse
}

\author{
Nasir Hussain, MSc, MD (1) - Tom Van den Langenbergh, MD • Corey Sermer, MSc • \\ Manuel L. Fontes, MD • Amit Atrey, MSc, MD, FRCS · Naum Shaparin, MD · \\ Tamara R. Sawyer, MSHAL, MLIS, AHIP • Amaresh Vydyanathan, MD \\ Received: 12 April 2017/Accepted: 2 November 2017/Published online: 21 November 2017 \\ (C) Canadian Anesthesiologists' Society 2017
}

\begin{abstract}
Purpose Dexamethasone is commonly used as an adjuvant to local anesthetics for peripheral nerve blockade; however, uncertainty persists regarding its optimal route of administration and safety. A systematic review and metaanalysis of randomized-controlled trials (RCTs) was
\end{abstract}

Electronic supplementary material The online version of this article (https://doi.org/10.1007/s12630-017-1008-8) contains supplementary material, which is available to authorized users.

N. Hussain, MSc, MD $(\varangle) \cdot$ T. R. Sawyer, MSHAL, MLIS, AHIP

Central Michigan University College of Medicine, CMED

Building, 1280 S. East Campus St, Mt. Pleasant, MI 48859, USA

e-mail: nasir.hussain@cmich.edu

T. Van den Langenbergh, MD

West Suffolk NHS Foundation Trust, Suffolk, England

C. Sermer, MSc

Faculty of Medicine, University of Toronto, Toronto, ON, Canada

M. L. Fontes, MD

Department of Anesthesiology, Yale School of Medicine, New Haven, CT, USA

A. Atrey, MSc, MD, FRCS

Department of Orthopaedics, St. Michael's Hospital, Toronto, ON, Canada

N. Shaparin, MD · A. Vydyanathan, MD

Department of Anesthesia, Montefiore Medical Center, Bronx, NY, USA conducted to compare the incremental benefits of intravenous $(I V)$ vs perineural $(P N)$ dexamethasone when used as adjuvants for peripheral nerve blockade to improve analgesia.

Sources A search strategy was developed to identify eligible articles from the Cochrane and National Library of Medicine databases from inception until June 2017. The National Center for Biotechnology Information Medical Subject Headings browser thesaurus was used to identify search terms and combinations of keywords. Any clinical trial that randomly allocated adult patients ( $\geq 18 \mathrm{yr}$ old) to receive either $I V$ or $P N$ dexamethasone for peripheral nerve blockade was considered for inclusion.

Principal findings After full-text screening of potentially eligible articles, 14 RCTs were included in this review. Overall, the use of $P N$ dexamethasone did not provide a significant incremental benefit to the duration of analgesia [ratio of means (ROM), 1.23; Hartung-Knapp-SidikJonkman (HKSJ) 95\% confidence interval (CI), 0.85 to 1.85; $P=0.23$ ] or to motor block duration (ROM, 1.14; HKSJ 95\% CI, 0.98 to 1.31; P = 0.07). Also, at 24-hr follow-up, there was no significant difference between the two groups regarding pain scores (standardized mean difference, 0.36; HKSJ 95\% CI, -0.08 to 0.80; $I^{2}=75 \%$; $P=0.09$ ) and cumulative opioid consumption (mean difference, $5.23 \mathrm{mg}$; HKSJ 95\% CI, 4.60 to 15.06; $P=$ 0.15). Lastly, no long-term nerve-related complications were observed with the use of PN dexamethasone.

Conclusions The results of our meta-analysis suggest that $P N$ and IV dexamethasone provide equivalent analgesic 
benefits and have similar safety profiles, when used as adjuvants, for peripheral nerve blockade.

\section{Résumé}

Objectif La dexaméthasone est fréquemment utilisée comme adjuvant aux anesthésiques locaux pour compléter les blocs nerveux périphériques; toutefois, sa voie d'administration optimale et son innocuité demeurent inconnues. Une revue systématique et une méta-analyse des études randomisées contrôlées (ERC) ont été réalisées afin de comparer les avantages distinctifs de la dexaméthasone administrée par voie intraveineuse (IV) vs périnerveuse (PN) lorsque ces modalités sont utilisées comme adjuvants à un bloc nerveux périphérique pour améliorer l'analgésie.

Source Une stratégie de recherche a été mise au point afin d'identifier les articles éligibles dans les bases de données Cochrane et de la National Library of Medicine depuis leur création et jusqu'au mois de juin 2017. Le thésaurus du navigateur de descripteurs médicaux (termes MeSH) du Centre national pour les renseignements biotechnologiques américain (National Center for Biotechnology Information) a été utilisé afin d'identifier les termes de recherche et les combinaisons de mots-clés. Le critère d'inclusion de notre étude était tout essai clinique ayant alloué aléatoirement des patients adultes (âgés de 18 ans ou plus) à recevoir de la dexaméthasone IV ou PN pour un bloc nerveux périphérique.

Constatations principales Après une lecture du texte intégral des articles potentiellement éligibles, 14 ERC ont été incluses dans cette revue. Globalement, l'utilisation de dexaméthasone $P N$ n'a pas procuré d'avantage supplémentaire significatif en matière de durée de l'analgésie [rapport de moyennes (RM), 1,23; intervalle de confiance (IC) $95 \%$ de Hartung-Knapp-Sidik-Jonkman (HKSJ), 0,85 à 1,85; $P=0,23$ ] ou de durée du bloc moteur (RM, 1,14; IC $95 \%$ HKSJ, 0,98à 1,31; P = 0,07). En outre, au suivi de $24 \mathrm{~h}$, il n'y avait aucune différence significative entre les deux groupes en matière de scores de douleur (différence moyenne standardisée, 0,36; IC $95 \%$ HKSJ, -0,08 à 0,80; $I^{2}=$ $75 \% ; P=0,09)$ et de consommation d'opiö̈des cumulée (différence moyenne, 5,23 mg; IC 95\% HKSJ, -4,60 à 15,06; P $=0,15)$. Enfin, aucune complication neurologique n'a été observée à long terme avec l'utilisation de dexaméthasone $P N$. Conclusion Les résultats de notre méta-analyse suggèrent que la dexaméthasone $P N$ et IV procurent des bienfaits analgésiques équivalents et affichent des profils d'innocuité semblables lors de leur utilisation pour un bloc nerveux périphérique.

Peripheral nerve block with local anesthetics has been shown to be an effective tool to increase analgesic effect

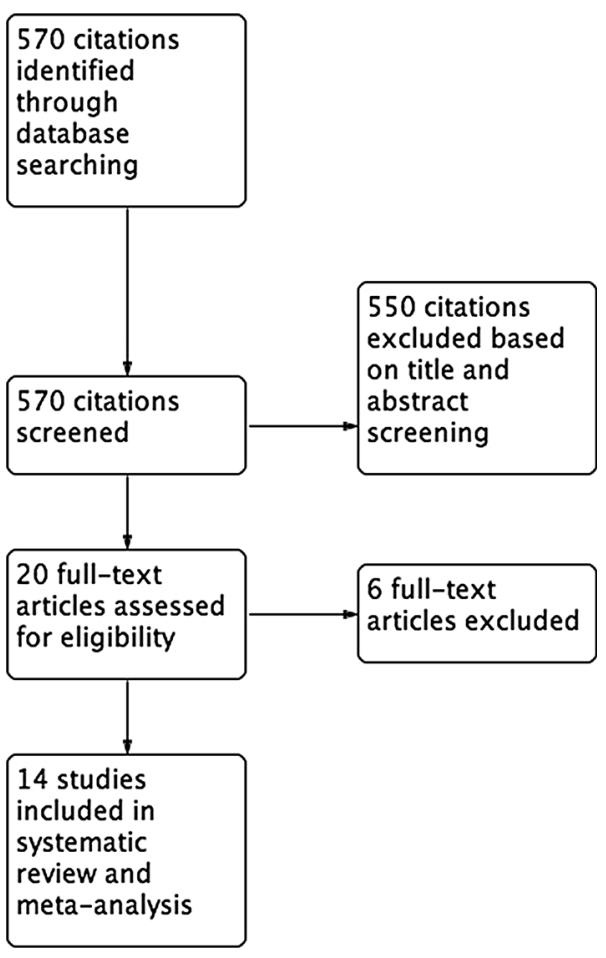

Fig. 1 Study flow diagram for study inclusion

and reduce patient use of opioid analgesics. ${ }^{1,2}$ Nevertheless, the duration of this effect is generally not long enough for adequate pain control in most patients. ${ }^{1,2}$ Another strategy to enhance the analgesic effect of local anesthetics is to add adjuvants such as epinephrine, clonidine, dexmedetomidine, and dexamethasone. The use of dexamethasone as an adjuvant to local anesthetics has emerged relatively recently, as studies have repeatedly shown that its addition to nerve blockade holds great potential to prolong the duration of analgesia. ${ }^{1,3-6}$ Even so, the optimal route of administration is still largely unknown. Some findings support perineural (PN) over intravenous (IV) dexamethasone for improving the duration of analgesia and for reducing postoperative analgesic consumption, ${ }^{7,8}$ whereas other studies have observed no difference between the two routes of administration. ${ }^{9,10}$ Moreover, there is concern that PN dexamethasone administration may cause direct nerve injury. ${ }^{10-12}$

Due to the uncertainty surrounding the use of PN $v s$ IV dexamethasone for prolonging the duration of analgesia, the optimal method to administer the drug remains a topic of debate. Thus, the primary objective of this meta-analysis was to evaluate the incremental benefit of PN vs IV dexamethasone for improving the duration of analgesia in adult patients ( $>18 \mathrm{yr}$ of age) undergoing peripheral nerve blockade. The secondary objectives were to compare the effectiveness of their routes of administration for motor block duration, improving pain control, decreasing 


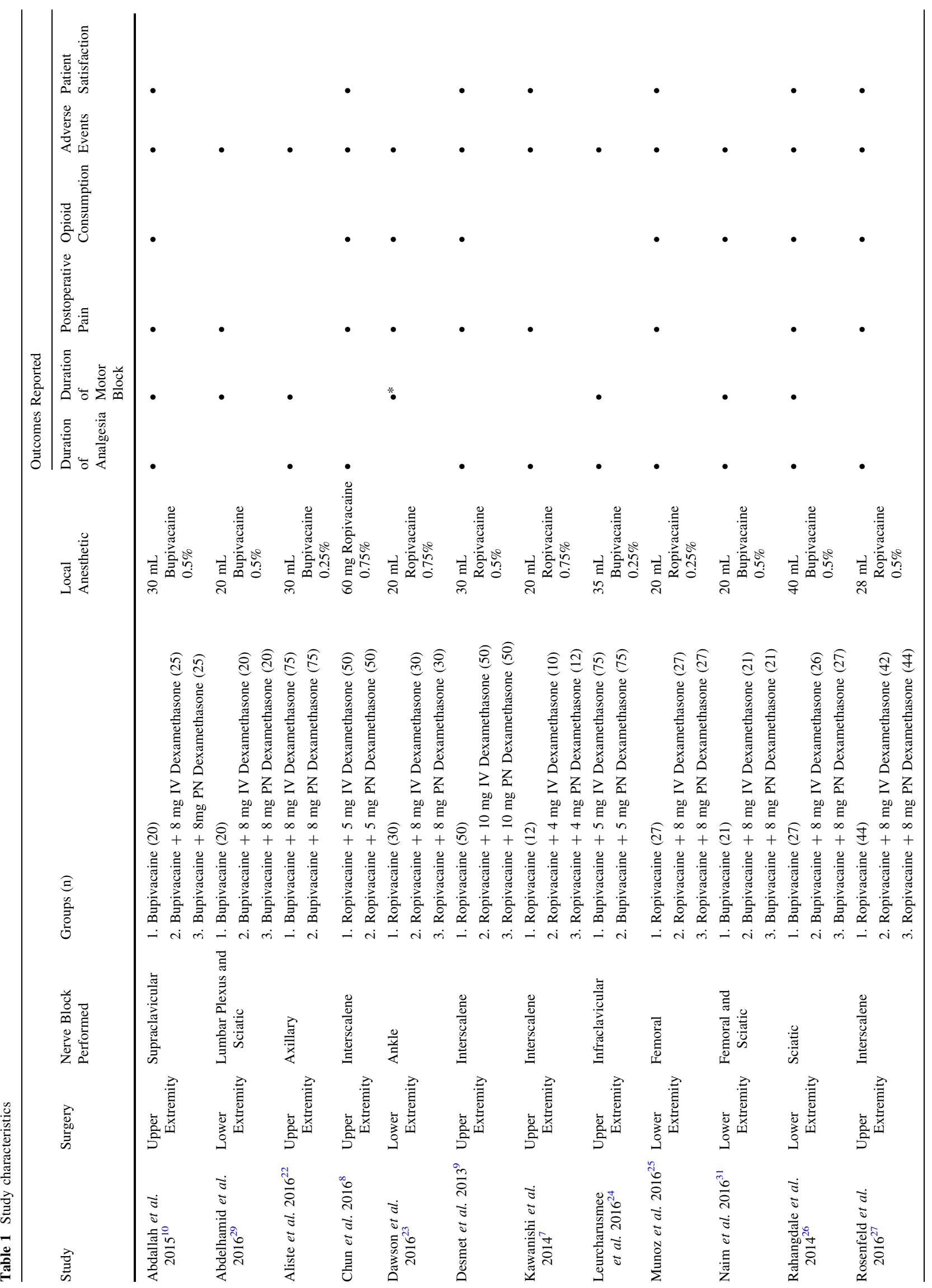




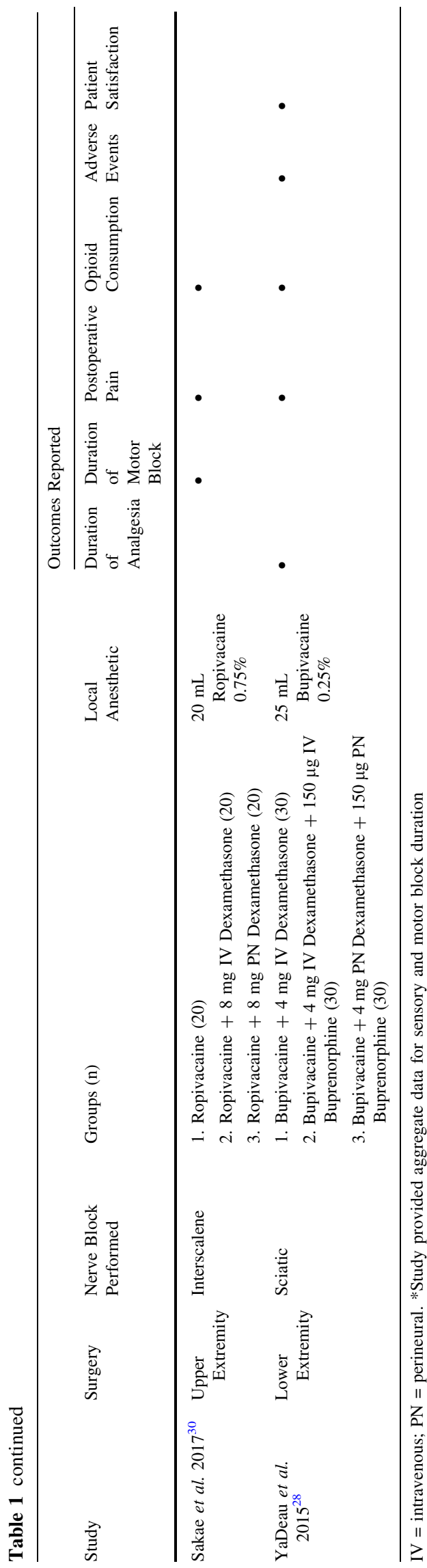

postoperative opioid consumption, and limiting overall adverse events.

\section{Methods}

Criteria for study inclusion

Any clinical trial that randomly allocated adult patients ( $\geq 18 \mathrm{yr}$ old) to receive either PN or IV dexamethasone for peripheral nerve blockade was considered for inclusion. Trials were excluded if they evaluated the efficacy of dexamethasone as an adjunct to local anesthesia $v s$ the use of local anesthesia alone. Studies were also excluded if continuous catheter-based nerve blocks were used. No language restrictions were placed on inclusion and nonEnglish articles were translated using an online translator.

Search methods for study identification

A librarian (T.R.S.) versed in evidence-based medicine created a search strategy for the Cochrane and National Library of Medicine databases from inception until June 20, 2017. The full search strategy can be viewed in Appendix A (available as Electronic Supplemental Material). The National Center for Biotechnology Information Medical Subject Headings browser thesaurus was used to identify search terms and combinations of keywords. All keywords were used as single search terms and in combination. Two independent reviewers (C.S. and T.V.D.L.) screened all abstracts that were retrieved through the electronic search strategy. Following this initial screening, the full-text versions of potentially eligible articles were retrieved and further evaluated for inclusion. In the case of disagreement, the two reviewers evaluated the full article and deliberated until a consensus was reached. When consensus could not be reached, a third reviewer (N.H.) assessed the article for eligibility. The reference lists of all eligible articles were hand-searched to help ensure that no clinical trial was missed. Intra-observer agreement between the two independent reviewers for fulltext eligibility was assessed by calculating an unweighted kappa ( $)$.

Primary and secondary outcomes

The primary outcome of this meta-analysis was the assessment of any difference in incremental benefit in the duration of analgesia from PN vs IV dexamethasone when used as adjuvants for peripheral nerve blockade. Secondary outcomes included motor block duration, postoperative pain at 24-hr follow-up, postoperative opioid consumption at $\geq 24$-hr follow-up, and the following adverse events: 


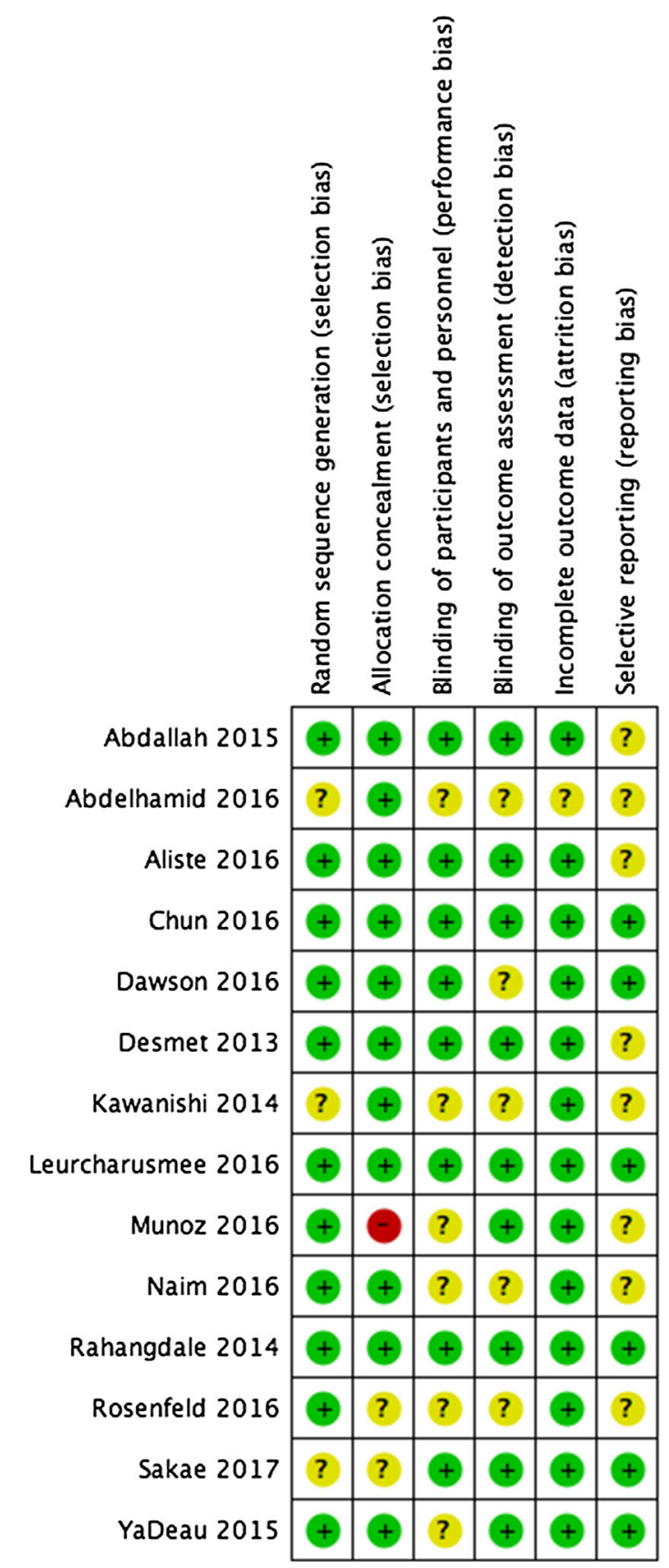

Fig. 2 Risk of bias assessment of trials included in the meta-analysis

nausea, vomiting, hyperglycemic episodes, and nerverelated complications.

Data management and extraction

An independent reviewer (C.S.) created and initially piloted a data extraction form. Two independent reviewers (N.H. and C.S.) performed data extraction to minimize the risk of error and to ensure accuracy. The following study-specific data were extracted: type of surgery; regional block and injection technique; dose of dexamethasone; type, concentration, and volume of local anesthetic; duration of analgesia as time from injection; motor block duration; sensory block duration; opioid consumption/morphine opioid equivalents (including follow-up time); postoperative pain score (including scale used to assess pain and follow-up time); and adverse events. Data reported in graphical form was extracted from a graph digitizer software (GraphClick, Arizona Software). The corresponding authors of all included studies were contacted as needed for additional data or summary statistics. Specifically, when data were reported as median [interquartile range (IQR)], further information was sought for mean (standard deviation [SD]). If no response was obtained, statistical conversions were made to a mean (SD) using the methods described by Wan et al. ${ }^{13}$ Data were excluded from analysis if the conversion could not be made.

\section{Risk of bias assessment}

Two independent reviewers (N.H. and C.S.) used the Cochrane Tool for Risk of Bias questionnaire to assess the methodological quality of all included randomized trials. ${ }^{14}$ In the case of disagreement between the two independent reviewers, a third reviewer (A.V.) assessed the study in question. Studies were evaluated based on their randomization techniques, blinding of study personnel/patients, incomplete outcome data, and selective outcome reporting. For each question in the tool, the study was classified as having a low, unclear, or high risk of bias. With regard to incomplete outcome data, studies were classified as low risk of bias if the follow-up rate was $\geq 80 \% .{ }^{14}$ For bias from selective outcome reporting, studies were classified as low risk of bias if trials were preregistered and their protocols were available for full review. ${ }^{14}$ The intra-observer agreement between the two independent reviewers on the risk of bias assessment was evaluated by calculating an unweighted $\kappa$.

Assessment of publication bias

A funnel plot was created and visually inspected to assess publication bias in the primary outcome. In the absence of significant bias, the plot should generally take the shape of a symmetrical inverted funnel.

Statistical analyses and measurement of treatment effect

When necessary, all time measurements were converted to hours to ensure consistent units between studies. To determine the overall effect size for all time-to-event outcomes (duration of analgesia and motor block duration), 


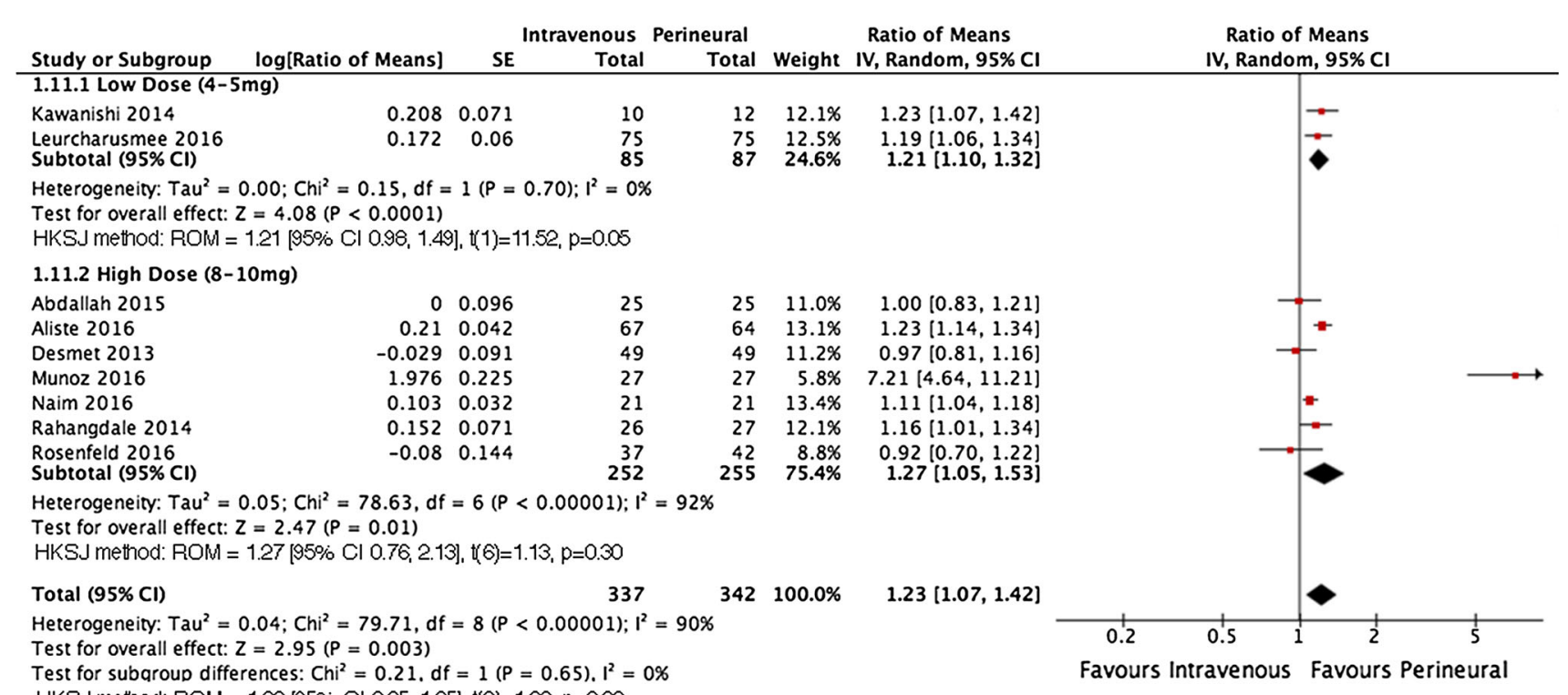

Fig. 3 Ratio of means (ROM) for analgesia duration with HartungKnapp-Sidik-Jonkman (HKSJ) 95\% confidence interval (CI) in patients receiving intravenous $v s$ perineural dexamethasone. Overall estimate of effect is shown in addition to the pooled estimates for subgroup analysis based on dosage of dexamethasone (low dose vs high dose)

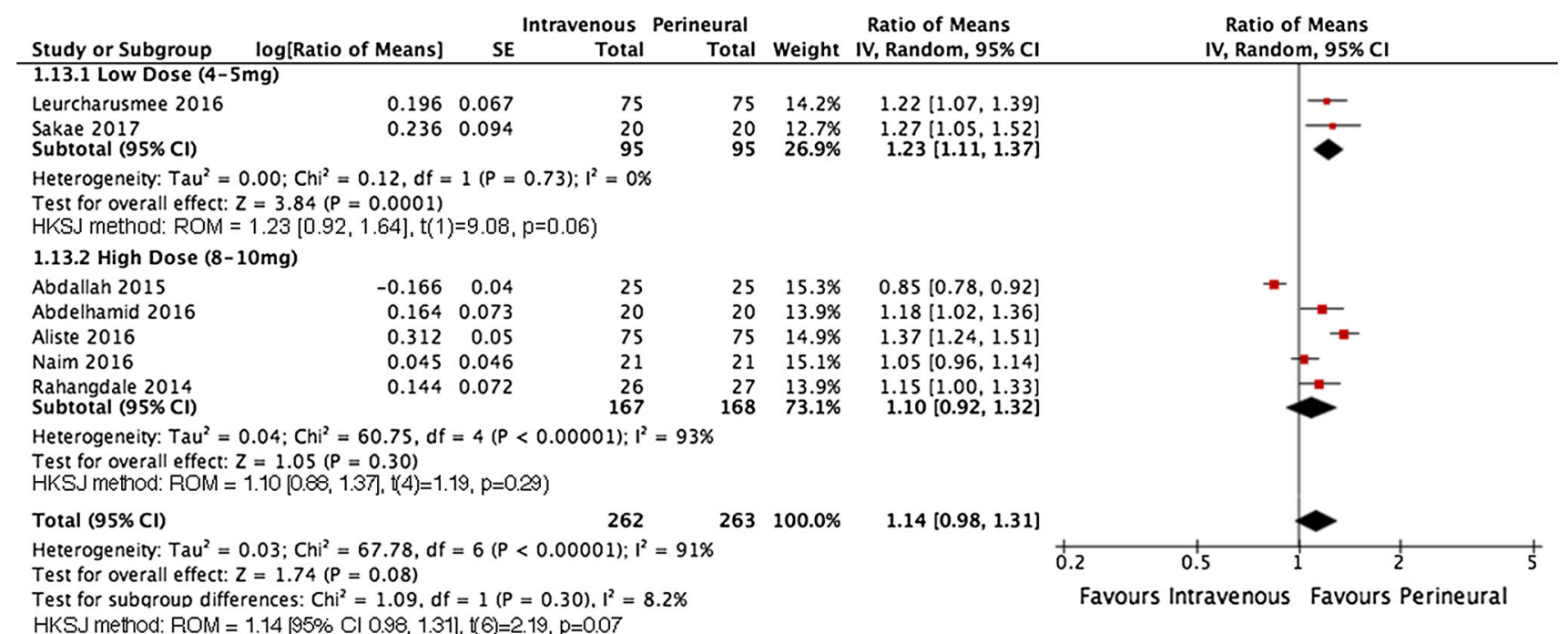

Fig. 4 Ratio of means (ROM) for motor block duration with Hartung-Knapp-Sidik-Jonkman (HKSJ) 95\% confidence interval (CI) in patients receiving intravenous $v s$ perineural dexamethasone.

a ratio of means (ROM) with a $95 \%$ confidence interval (CI) was calculated.

For analysis of postoperative pain, a standard mean difference (SMD) with a 95\% CI was calculated, and for total opioid consumption ( $\mathrm{mg}$ ) and change in postoperative glucose level $\left(\mathrm{mg} \cdot \mathrm{dL}^{-1}\right)$, a mean difference (MD) with a 95\% CI was calculated. Nausea/vomiting and nerve-related complications were analyzed categorically and reported as a risk ratio $(\mathrm{RR})$ with a $95 \% \mathrm{CI}$.
Overall estimate of effect is shown in addition to the pooled estimates for subgroup analysis based on dosage of dexamethasone (low dose $v s$ high dose)

Statistical pooling of data was performed only when there were two or more studies for a given outcome. All outcome data were initially pooled using the DerSimonian and Laird random effects model; however, due to expected heterogeneity and the limited number of studies, we conducted further post hoc analysis using the HartungKnapp-Sidik-Jonkman (HKSJ) method for random effects, as described by IntHout et al. ${ }^{15}$ Studies have found the HKSJ method to be better suited than the DerSimonian and 


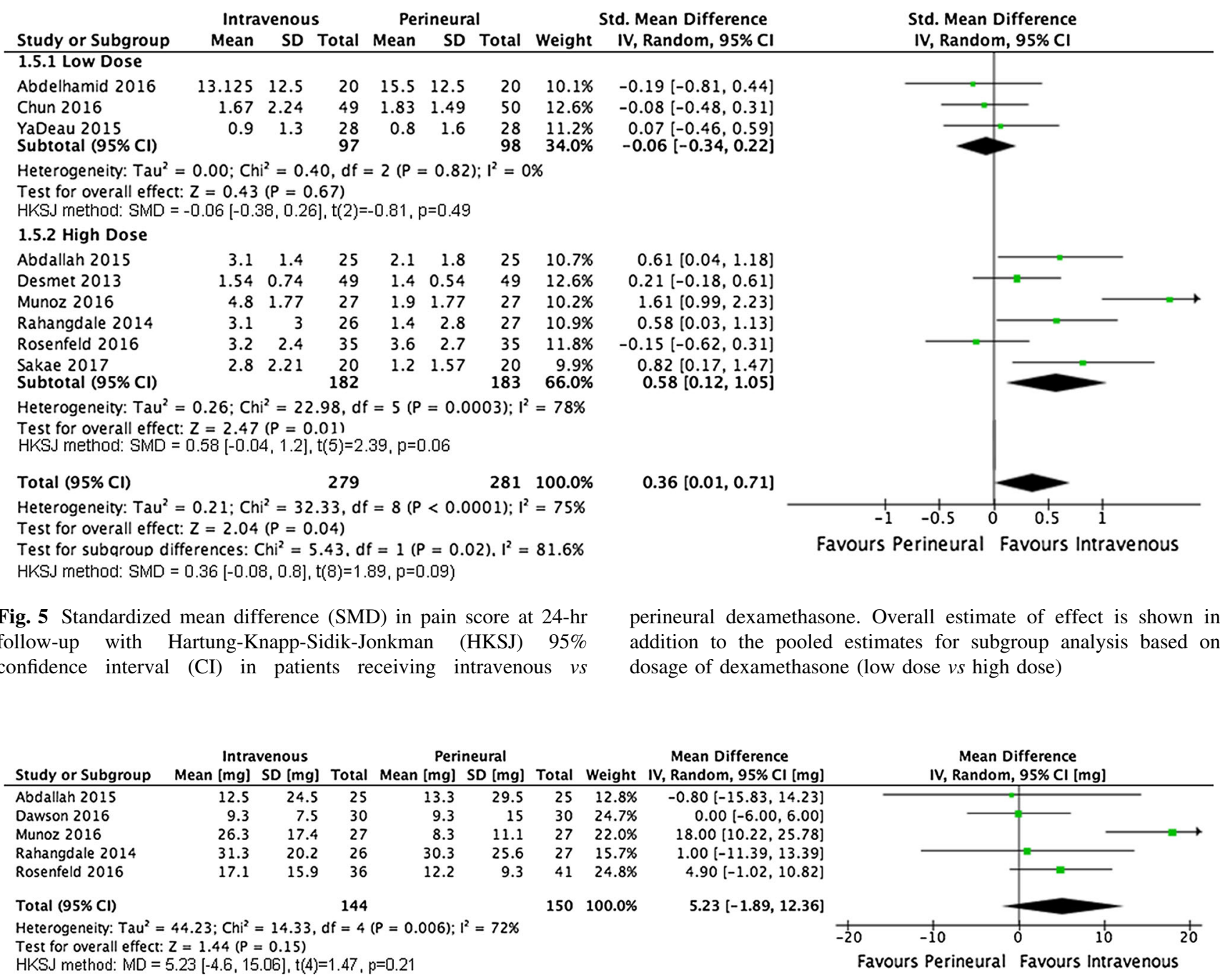

Fig. 6 Mean opioid consumption in milligrams (mg) at $\geq 24$-hr follow-up with Hartung-Knapp-Sidik-Jonkman (HKSJ) 95\% confidence interval (CI) in patients receiving intravenous vs perineural dexamethasone

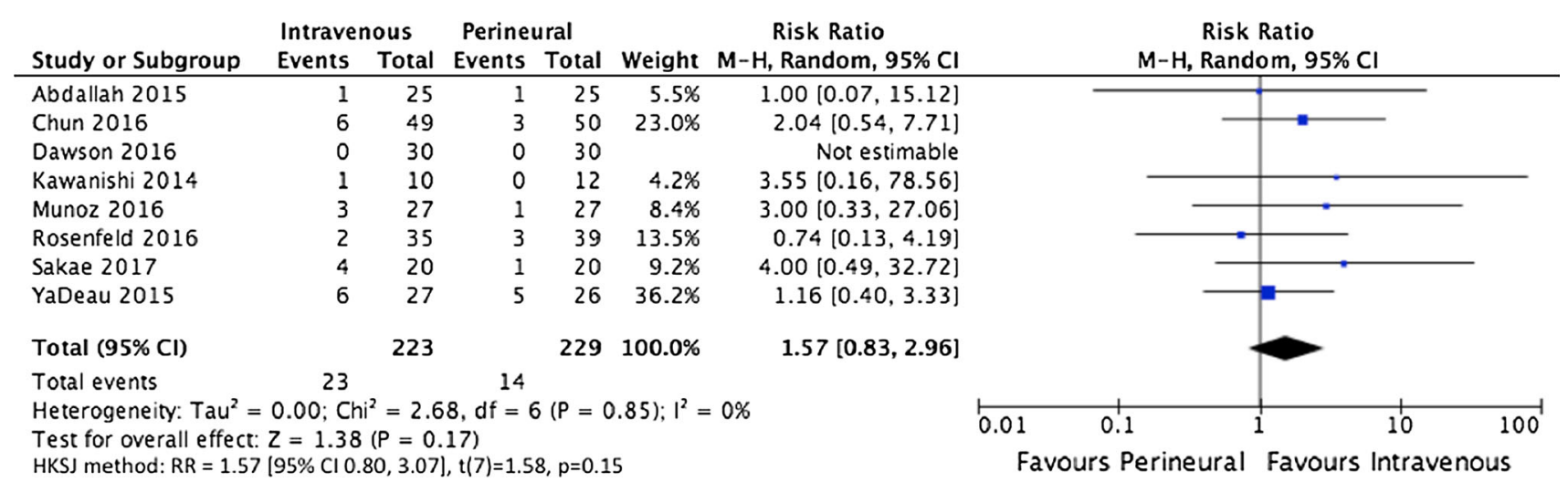

Fig. 7 Mean risk ratio (RR) of nausea and vomiting with Hartung-Knapp-Sidik-Jonkman (HKSJ) 95\% confidence interval (CI) in patients receiving intravenous $v s$ perineural dexamethasone

Laird random effects model for meta-analyses with a limited number of studies due to its conservative estimates of between-study variance. ${ }^{15,16}$ Furthermore, error rates (i.e., the percentage of statistically significant metaanalyses when the overall mean treatment difference is zero) have been found to be lower with the HSJK method 
Table 2 Reported neurological adverse events from included trials in meta-analysis

\begin{tabular}{|c|c|c|c|c|}
\hline \multirow[t]{2}{*}{ Study } & \multicolumn{2}{|l|}{ Intravenous Dexamethasone } & \multicolumn{2}{|l|}{ Perineural Dexamethasone } \\
\hline & Complication & $\begin{array}{l}\text { Number of } \\
\text { Patients } \\
(n=378)\end{array}$ & Complication & $\begin{array}{l}\text { Number of } \\
\text { Patients } \\
(n=385)\end{array}$ \\
\hline Abdallah et al. $2015^{10}$ & None reported & & None reported & \\
\hline Aliste et al. $2016^{22}$ & $\begin{array}{l}\text { Residual digital paresthesia } \\
\text { (1 week postoperatively) }\end{array}$ & 1 & & \\
\hline \multirow[t]{2}{*}{ Chun et al. $2016^{8}$} & Numbness (24-48 hr postoperatively) & 1 & Numbness (24-48 hr postoperatively) & 2 \\
\hline & Diaphragm elevation & 1 & Diaphragm elevation & 2 \\
\hline \multirow[t]{3}{*}{ Desmet et al. $2013^{9}$} & Horner Syndrome & 20 & Horner Syndrome & 24 \\
\hline & Hoarseness & 11 & Hoarseness & 11 \\
\hline & & & Hypoesthesia in the deltoid region* & 1 \\
\hline Kawanishi et al. $2014^{7}$ & None reported & & None reported & \\
\hline Leurcharusmee et al. $2016^{24}$ & None reported & & None reported & \\
\hline Munoz et al. $2016^{25}$ & None reported & & None reported & \\
\hline \multirow[t]{3}{*}{ Rahangdale et al. $2014^{26}$} & Dysesthesia (2 weeks postoperatively) & 1 & Paresthesia ( 2 weeks postoperatively) & 2 \\
\hline & Numbness ( 2 weeks postoperatively) & 2 & Numbness (2 weeks postoperatively) & 2 \\
\hline & $\begin{array}{l}\text { Numbness (4 weeks } \\
\text { postoperatively) }\end{array}$ & 2 & $\begin{array}{r}\text { Numbness ( } 4 \text { weeks } \\
\text { postoperatively) } \Omega\end{array}$ & 1 \\
\hline Rosenfeld et al. $2016^{27}$ & & & Hoarseness $\dagger$ & 1 \\
\hline YaDeau et al. ${ }^{28}$ & Numbness (30 days postoperatively) & 1 & Numbness (30 days postoperatively & 1 \\
\hline Total & & 40 & & 47 \\
\hline
\end{tabular}

Total number of patients with an adverse event are listed

*Study reported that this adverse event was due to disc herniation at the level of C4-5 with a disc-radicular conflict

$\sum$ Symptoms resolved with surgical intervention

$\Omega$ Symptoms resolved by six-week follow-up

$\dagger$ Reported adverse event was not directly attributable to nerve blockade or dexamethasone administration

when substantial heterogeneity $\left(\mathrm{I}^{2}=90 \%\right)$ is present. ${ }^{15}$ The 95\% CIs from the HKSJ method have been reported in this review.

Assessment of heterogeneity

An $\mathrm{I}^{2}$ threshold of $40 \%$ was used for conducting subgroup analysis. ${ }^{14}$ If heterogeneity was present, a priori subgroup analysis was performed on the basis of dexamethasone dose, which was stratified as being low (4-5 mg) or high (8$10 \mathrm{mg}$ ). It has been thought that IV administration of dexamethasone requires higher doses to achieve analgesia, whereas lower PN doses are needed to achieve similar effects. ${ }^{17-21}$ Subgroup analyses were performed only if each subgroup had $\geq$ two studies present.

\section{Data management}

Review Manager software (RevMan version 5.2; Nordic Cochrane Centre, Cochrane Collaboration) was used to generate the forest and funnel plots presented in this review. Intra-observer agreement between independent reviewers, as assessed through the unweighted $\kappa$, was calculated using SPSS ${ }^{\circledR}$ software version 21.0 (SPSS Inc., Chicago, IL, USA). All tests of significance were twotailed, and $P$ values $<0.05$ were considered significant.

\section{Results}

Study characteristics

The primary literature search initially identified 570 articles. After the initial title and abstract review, 550 articles were excluded because of the inclusion of animals, incorrect group comparison, or non-randomization. Subsequently, 20 articles were assessed for full-text eligibility. Six of these were excluded because they either assessed the role of dexamethasone as an adjuvant for peripheral nerve blockade without comparing the routes of administration or were commentaries. Thus, $14^{7-10,22-31}$ randomized-controlled trials (RCTs) satisfied the full inclusion criteria. The unweighted $\kappa$, as calculated for the level of agreement between the two independent reviewers, 
was found to be 0.77. A full flow diagram of study inclusion can be viewed in Fig. 1.

All 14 studies included in this review were conducted at various centres in the United States, Canada, Europe, Asia, and South America. In all, 501 and 506 subjects were randomized to receive IV dexamethasone or PN dexamethasone, respectively. Eight of the trials evaluated the efficacy of IV vs PN dexamethasone on prolonging the duration of analgesia for upper extremity procedures, ${ }^{7-10,22,24,27,29}$ while six analyzed the comparison for lower extremity procedures. ${ }^{23,25,26,28,30,31}$ The type of peripheral nerve blocks performed included interscalene, ${ }^{7-9,27,30}$ sciatic, ${ }^{26,28}$ supraclavicular, ${ }^{10}$ axillary, ${ }^{22}$ infraclavicular, ${ }^{24}$ femoral, ${ }^{25}$ ankle, ${ }^{23}$ combined lumbar plexus and sciatic, ${ }^{29}$ and combined femoral and sciatic. ${ }^{31}$ The local anesthetic used for the peripheral nerve block also varied across the studies, with seven utilizing bupivacaine ${ }^{10,22,24,26,28,29,31}$ and seven utilizing ropivacaine. ${ }^{7-9,23,25,27,30}$ One study ${ }^{28}$ also added IV or PN buprenorphine to the mixture of local anesthetics and dexamethasone. The studies also differed on the dose of dexamethasone used; these included $10 \quad \mathrm{mg},{ }^{9} \quad 8$ $\mathrm{mg},{ }^{10,22,23,25-27,29,31} 5 \mathrm{mg},{ }^{8,24}$ and $4 \mathrm{mg}{ }^{7,28,30}$ Table 1 shows characteristics of all included studies, and Appendix B (available as Electronic Supplementary Material) contains the individual results of these studies.

The corresponding authors of select studies were contacted to obtain additional data that would allow for the generation of a more accurate estimate of effect. Three studies ${ }^{9,26,27}$ provided their complete dataset. One ${ }^{10}$ study responded to our requests and provided us with mean and SDs for the outcomes reported as median and IQR.

Risk of bias assessment of included studies

Across all included studies, most methodological quality parameters were classified as "low" risk of bias. It is noteworthy that six of the trials were preregistered with clinical trial registries and had associated protocols available for review. ${ }^{8,9,24,26,28,30}$ The unweighted $\kappa$ between the two independent reviewers assessing the risk of bias of all included studies was 0.72. A diagram depicting the final risk of bias assessment across all parameters can be seen in Fig. 2. Visual inspection of the funnel plot for the primary outcome, duration of analgesia, did not suggest publication bias (Appendix C; available as Electronic Supplementary Material).

Duration of analgesia

Duration of analgesia was assessed in 11 studies, with five ${ }^{10,22,24,26,28}$ defining the outcome as time to first sensation of pain and $\operatorname{six}^{7-9,25,27,31}$ defining the outcome as time to first analgesic request. Two studies ${ }^{8,28}$ reported the outcome with measures that were not amenable to statistical pooling, and one study ${ }^{7}$ had their data converted to a mean and SD. As such, data from nine studies $^{7,9,10,22,24-27,31}$ including 679 patients (PN 342, IV 337) were analyzed. Overall, PN dexamethasone appeared to prolong the duration of analgesia by an additional 23\%; however, the difference was not statistically significant (ROM, 1.23; HSJK 95\% CI, 0.85 to $1.85 ; \mathrm{I}^{2}=90 \%, P=$ 0.23, Fig. 3).

Subgroup analysis was performed as per our a priori hypothesis since heterogeneity was above the predefined cut-off. No significant difference was found between PN and IV dexamethasone regardless of using low (4-5 mg) ${ }^{7,24}$ (ROM, 1.21; HSJK 95\% CI, 0.98 to $1.49 ; \mathrm{I}^{2}=0 \% ; P=$ $0.05)$ or high $(8-10 \mathrm{mg})^{9,10,22,25-27,31}(\mathrm{ROM}, 1.27$; HSJK $95 \%$ CI, 0.76 to $2.13 ; \mathrm{I}^{2}=92 \% ; P=0.30$ ) doses (Fig. 3).

\section{Duration of motor block}

Eight studies ${ }^{10,22-24,26,29-31}$ assessed motor block duration. The data from one ${ }^{23}$ of these studies were excluded from analysis since the authors reported overall block duration and did not stratify their data based on either sensory or motor block durations. As such, seven studies ${ }^{10,22,24,26,29-31}$ including 525 patients (PN 263, IV 262) were analyzed. Perineural dexamethasone appeared to prolong motor block duration by an additional 14\%; however, the difference was not statistically significant (ROM, 1.14; HSJK 95\% CI, 0.98 to $1.31 ; \mathrm{I}^{2}=91 \% ; P=0.07$, Fig. 4).

Subgroup analysis was performed as per our a priori hypothesis since heterogeneity was above the predefined cut-off. No significant difference was found between PN and IV dexamethasone regardless of using low (4-5 $\mathrm{mg})^{24,30}$ (ROM, 1.23; HSJK 95\% CI, 0.92 to $1.64 ; \mathrm{I}^{2}=$ $0 \% ; P=0.06)$ or high $(8-10 \mathrm{mg})^{10,22,26,29,31}(\mathrm{ROM}, 1.10$; HSJK 95\% CI, 0.88 to $1.37 ; \mathrm{I}^{2}=93 \% ; P=0.29$ ) doses (Fig. 4).

Postoperative pain scores at 24-hr follow-up

Nine studies assessed postoperative pain at 24-hr followup..$^{8-10,25-30}$ Five of these studies ${ }^{10,25,27,29,30}$ used the visual analogue scale, while three $e^{8,26,28}$ used the numeric rating scale, and one ${ }^{9}$ utilized the verbal rating scale. Two studies $^{8,29}$ had their data converted to mean and SD. As such, nine studies ${ }^{8-10,25-30}$ including 560 patients (PN 281, IV 279) were analyzed. Overall, no significant difference was observed in pain scores at 24-hr follow-up between patients receiving PN vs IV dexamethasone (SMD, 0.36; HSJK 95\% CI, -0.08 to $0.80 ; \mathrm{I}^{2}=75 \% ; P=0.09$, Fig. 5).

Subgroup analysis as per our a priori hypothesis was carried out since the heterogeneity was above the 
predefined cut-off. No significant difference in postoperative pain at 24-hr follow-up was found between PN and IV dexamethasone regardless of using low (4-5 $\mathrm{mg})^{8,28,29}$ (SMD, -0.06; HSJK 95\% CI, -0.38 to $0.26 ; \mathrm{I}^{2}=$ $0 \% ; P=0.49)$ or high $(8-10 \mathrm{mg})^{9,10,25-27,30}$ (SMD, 0.58; HSJK $95 \% \mathrm{CI},-0.04$ to $\left.1.20 ; \mathrm{I}^{2}=78 \% ; P=0.06\right)$ doses (Fig. 5).

\section{Cumulative opioid consumption at $\geq 24$-hr follow-up}

Ten studies ${ }^{8-10,23,25-28,30,31}$ assessed opioid consumption at $\geq 24$-hr follow-up. Three studies ${ }^{8,28,30}$ did not report cumulative opioid use at $\geq 24$-hr follow-up but rather reported the total number of patients requiring opioids. One study $^{9}$ did not report mean values for opioid consumption since only seven patients required opioids, and one study ${ }^{31}$ prescribed opioid rescue analgesics for postoperative pain but did not report the cumulative mean amount given. Thus, five studies ${ }^{10,23,25-27}$ including 294 patients (PN 150, IV 144) evaluating postoperative opioid consumption at $\geq$ 24-hr follow-up were included in the analysis. Perineural dexamethasone appeared to reduce postoperative opioid consumption at $\geq 24$-hr follow-up by $5.23 \mathrm{mg}$; however, the difference was not statistically significant (MD, 5.23 mg; HSJK 95\% CI, -4.60 to $15.06 ; \mathrm{I}^{2}=72 \% ; P=0.21$, Fig. 6). Although heterogeneity was above our predefined cut-off, subgroup analysis was not performed since each subgroup did not contain $\geq$ two studies.

\section{Adverse events or block-related complications}

The most commonly reported adverse event was nausea and vomiting. Eight studies $7,8,10,23,25,27,28,30$ assessed nausea and vomiting postoperatively in 452 patients (PN 229, IV 223). Although the risk of postoperative nausea and vomiting was increased by 1.57 times with IV dexamethasone administration, the difference between the groups was not statistically significant (RR, 1.57; HSJK 95\% CI, 0.8 to $3.0 .7 ; \mathrm{I}^{2}=0 \% ; P=0.15$, Fig. 7). Subgroup analysis was not performed since the heterogeneity did not meet our predefined threshold.

Three studies assessed perioperative glucose levels. ${ }^{8,9,25}$ One study ${ }^{25}$ reported that three patients who received IV dexamethasone suffered from hyperglycemia, whereas no occurrences were seen in the PN group. Two studies ${ }^{8,9}$ reported a change in glucose levels from baseline $(n=$ 197). Although both studies ${ }^{8,9}$ reported a mean increase in blood glucose values regardless of route of administration, no significant difference was observed between the two groups (MD, $1.43 \mathrm{mg} \cdot \mathrm{dL}^{-1}$; HSJK $95 \% \mathrm{CI},-2.55$ to 5.41 ; $\left.\mathrm{I}^{2}=0 \% ; P=0.13\right)$. Due to the limited number of studies included in this outcome, subgroup and sensitivity analysis was not performed.
Ten studies ${ }^{7-10,22,24-28}(n=763)$ assessed nerve-related complications at several different follow-up times, with six 8,9,22,26-28 reporting nerve palsies, paresthesias, and numbness (Table 2). In four of these studies, ${ }^{8,9,22,27}$ nerve injuries were transient and resolved by one month followup. On the other hand, two studies ${ }^{26,28}$ reported numbness that persisted beyond one month. In both studies, ${ }^{26,28}$ the numbness resolved at a later follow-up time. In the IV group, 40/378 patients experienced a neurological complication vs $47 / 385$ patients in the PN group. Overall, no significant difference in the risk of developing postoperative nerve-related complications was found between the two groups (RR, 0.87; HSJK 95\% CI, 0.71 to $\left.1.06 ; \mathrm{I}^{2}=0 \% ; P=0.13\right)$.

\section{Discussion}

In summary, the results of this meta-analysis suggest that, irrespective of dose, the use of PN dexamethasone does not appear to provide a significant incremental benefit to the duration of analgesia or motor blockade when compared with the use of IV dexamethasone. Furthermore, our findings suggest that, irrespective of dose, PN dexamethasone does not appear to provide a significant incremental benefit to postoperative pain and cumulative opioid consumption at $\geq 24$-hr follow-up. Finally, PN dexamethasone does not appear to lead to long-term neurologic complications.

The addition of dexamethasone to regional anesthetics such as lidocaine, bupivacaine, and other sodium channelblocking anesthetics has been shown to prolong the duration of analgesia. ${ }^{5,11,32-37}$ Recently, a meta-analysis of nine randomized trials by Choi et al. ${ }^{1}$ found that the addition of dexamethasone to regional anesthetics prolongs the duration of analgesia by approximately six hours. Furthermore, they reported a trend towards decreased opioid consumption. ${ }^{1}$ Although the mechanism involved in its prolongation of analgesia is poorly understood, a systemic effect is suggested. ${ }^{5}$ The underlying mechanisms may include the inhibition of nociceptive $\mathrm{C}$ fibres $^{5,23}$ and/or an anti-inflammatory effect. ${ }^{5}$

As with its mechanism of action, the optimal dose of dexamethasone for peripheral nerve blockade also remains to be resolved. Woo et al. ${ }^{21}$ compared the effectiveness of differing doses of PN dexamethasone for prolonging the duration of analgesia and reported that $5 \mathrm{mg}$ of $\mathrm{PN}$ dexamethasone provided $24.2 \mathrm{hr}$ of analgesia, while larger doses offered no additional benefit. ${ }^{21}$ Indeed, our findings also show a comparable incremental prolongation of analgesia between low-dose and higher dose dexamethasone when administered perineurally. There are also intriguing reports suggesting that the $95 \%$ 
effective dose may be even as low as 1-2 mg for PN dexamethasone and higher than $0.1 \mathrm{mg} \cdot \mathrm{kg}^{-1}$ for its IV use. $^{17,18}$ A meta-analysis conducted by De Oliveira et al. ${ }^{19}$ found that systemic dexamethasone achieves optimal analgesic effects when the dose is greater than 0.1 $\mathrm{mg} \cdot \mathrm{kg}^{-1}$; in contrast, higher doses (8-10 $\left.\mathrm{mg}\right)$ of dexamethasone provide no additional benefit. Future studies should focus on evaluating the dose-dependent analgesic effects of PN and IV dexamethasone administration.

The results of our meta-analysis differ from prior reviews $^{38,39}$ which have shown that the use of PN dexamethasone significantly prolongs the duration of analgesia to a greater degree than the use of IV dexamethasone. It is noteworthy that both reviews ${ }^{38,39}$ utilized the DerSimonian-Laird random effects model which has been found to have higher mean error rates in comparison with the HSJK method when substantial heterogeneity is present. ${ }^{15}$ In a review comparing both the HSJK and DerSimonian-Laird methods for Cochrane Reviews, it was found that $25.1 \%$ of findings that showed significance using the DerSimonian-Laird method failed to show significance using the HSKJ method. ${ }^{15}$ Our utilization of the HSKJ method ${ }^{15,16}$ provides a more conservative estimate of effect, which more likely reflects the true difference between PN and IV dexamethasone. Furthermore, the prior reviews ${ }^{38,39}$ utilized mean and standardized mean differences for time-to-event data. Our decision to use the ROM for time-to-event data stemmed from prior studies ${ }^{40,41}$ which have shown equivalence in statistical performance with improved clinical interpretability. Nevertheless, given the difference in our point estimates from prior reviews, ${ }^{38,39}$ the validity of our choice to use relative differences (i.e., ROM) in preference to difference-based methods would need to be confirmed by studying the probability of distributions for the duration of analgesia. ${ }^{42,43}$

Finally, it is extremely important to determine whether PN dexamethasone causes neuronal injury. Several investigators have addressed this. Williams et al. ${ }^{44}$ evaluated in vitro toxicity of PN adjuvants to ropivacaine in a rat model. In their study, the administration of supratherapeutic doses of dexamethasone $\left(667 \mu \mathrm{g} \cdot \mathrm{mL}^{-1}\right)$ for two hours did not result in detectable neuronal cell death. $^{44}$ Similarly, the addition of dexamethasone to ropivacaine did not increase neuronal cell death compared with ropivacaine alone. ${ }^{44}$ Williams et al. ${ }^{45}$ also evaluated in vivo local tissue effects of dexamethasone (66 $\left.\mu \mathrm{g} \cdot \mathrm{mL}^{-1}\right)$ and reported no evidence of behavioural changes in their rat model at one or 15 days. ${ }^{45}$ Furthermore, histopathological examination in these animals revealed no changes in the neuronal architecture. ${ }^{45}$ Although it is difficult to translate animal studies to humans, the results from our meta-analysis are consistent with these findings since no persistent neurological deficits were reported by any of the included RCTs.

Study strengths and limitations

Our meta-analysis comes with several notable strengths. First, we evaluated and compared the use of PN vs IV dexamethasone for peripheral nerve blockade on a variety of outcomes. In addition, we incorporated the HSJK random effects model into our analysis and generated novel results that are potentially more accurate than those previously reported. Another strength of this meta-analysis is that we obtained additional data from the authors of included studies which were not previously made available to readers. This allowed us to provide larger estimates of effects; however, the confidence intervals for some of our point estimates remained large, which limits external validity and a true differentiation between $\mathrm{PN}$ and IV dexamethasone.

Our review has several limitations. First, our subgroup analysis did not show a reduction in heterogeneity to levels below those of our predefined threshold values. This may have been due to factors such as the formulation of dexamethasone, amount/types of local anesthetics, inclusion of adjuvants to nerve blocks, and the sites used for the peripheral nerve blocks. Furthermore, the definition of outcomes and the methods used for their measurement varied across the studies. Additionally, several data points were converted from median and IQR to a mean and SD. Median and IQR are often reported for data that do not follow a normal distribution. As a result, this conversion may have skewed the data in a way that reduced accuracy. Finally, there may be an inadequate number of patients studied to determine the true incidence of rare adverse effects of PN dexamethasone.

\section{Conclusions}

Clinical consensus is lacking with regard to the optimal route of administration and dosage of dexamethasone for enhancing peripheral nerve blockade. The results of this meta-analysis suggest that, irrespective of dose, the use of PN dexamethasone does not appear to provide a significant incremental benefit to the duration of analgesia or motor blockade when compared with the use of IV dexamethasone. Similarly, PN dexamethasone does not appear to provide a significant incremental benefit in terms of pain control at 24-hr follow-up and opioid consumption at $>24$-hr follow-up, regardless of dose. Furthermore, our analysis did not reveal any long-term neurological adverse events related to the use of PN dexamethasone. Taken 
together, the results of our meta-analysis suggest that PN and IV dexamethasone provide equivalent analgesic benefits and have similar safety profiles when used as adjuvants for peripheral nerve blockade.

Acknowledgements We sincerely thank all the corresponding authors who graciously provided us with their data for this metaanalysis. The authors also thank Aamir Ahmed for his contributions to the manuscript.

Conflicts of interest None declared.

Editorial responsibility This submission was handled by Dr. Steven Backman, Associate Editor, Canadian Journal of Anesthesia.

\begin{abstract}
Author contributions Nasir Hussain and Amaresh Vydyanathan were involved in concept development. Nasir Hussain, Tom Van den Langenbergh, Corey Sermer, Manuel L Fontes, Amit Atrey, Naum Shaparin, and Amaresh Vydyanathan were involved in manuscript preparation. Nasir Hussain, Tom Van den Langenbergh, Corey Sermer, and Tamara $R$. Sawyer were involved in methods development. Nasir Hussain was involved in data collection and statistical analyses.
\end{abstract}

Financial support and sponsorship None.

\section{References}

1. Choi S, Rodseth R, McCartney CJ. Effects of dexamethasone as a local anaesthetic adjuvant for brachial plexus block: a systematic review and meta-analysis of randomized trials. $\mathrm{Br} \mathrm{J}$ Anaesth 2014; 112: 427-39.

2. Fredrickson MJ, Krishnan S, Chen $C Y$. Postoperative analgesia for shoulder surgery: a critical appraisal and review of current techniques. Anaesthesia 2010; 65: 608-24.

3. Castillo J, Curley J, Hotz J, et al. Glucocorticoids prolong rat sciatic nerve blockade in vivo from bupivacaine microspheres. Anesthesiology 1996; 185: 1157-66.

4. Drager C, Benziger D, Gao F, Berde CB. Prolonged intercostal nerve blockade in sheep using controlled-release of bupivacaine and dexamethasone from polymer microspheres. Anesthesiology 1998; 89: 969-79.

5. Movafegh A, Razazian M, Hajimaohamadi F, Meysamie A. Dexamethasone added to lidocaine prolongs axillary brachial plexus blockade. Anesth Analg 2006; 102: 263-7.

6. Kopacz DJ, Lacouture PG, Wu D, Nandy $P$, Swanton R, Landau $C$. The dose response and effects of dexamethasone on bupivacaine microcapsules for intercostal blockade (T9 to T11) in healthy volunteers. Anesth Analg 2003; 96: 576-82.

7. Kawanishi R, Yamamoto K, Tobetto $Y$, et al. Perineural but not systemic low-dose dexamethasone prolongs the duration of interscalene block with ropivacaine: a prospective randomized trial. Local Reg Anesth 2014; 7: 5-9.

8. Chun EH, Kim YJ, Woo JH. Which is your choice for prolonging the analgesic duration of single-shot interscalene brachial blocks for arthroscopic shoulder surgery? Intravenous dexamethasone 5 $\mathrm{mg}$ vs. perineural dexamethasone $5 \mathrm{mg}$ randomized, controlled, clinical trial. Medicine (Baltimore) 2016; 95: e3828.

9. Desmet M, Braems H, Reynvoet $M$, et al. I.V. and perineural dexamethasone are equivalent in increasing the analgesic duration of a single-shot interscalene block with ropivacaine for shoulder surgery: a prospective, randomized, placebo-controlled study. Br J Anaesth 2013; 111: 445-52.

10. Abdallah FW, Johnson $J$, Chan $V$, et al. Intravenous dexamethasone and perineural dexamethasone similarly prolong the duration of analgesia after supraclavicular brachial plexus block: a randomized, triple-arm, double-blind, placebo-controlled trial. Reg Anesth Pain Med 2015; 40: 125-32.

11. Martinez V, Fletcher D. Dexamethasone and peripheral nerve blocks: on the nerve or intravenous? Br J Anaesth 2014; 113: 338-40.

12. Albrecht E, Kern C, Kirkham KR. Perineural vs intravenous administration of dexamethasone: more data are available. Br J Anaesth 2015; 114: 160.

13. Wan $X$, Wang $W$, Liu J, Tong $T$. Estimating the sample mean and standard deviation from the sample size, median, range and/or interquartile range. BMC Med Res Methodol 2014; 14: 135.

14. Higgins JP, Green S. Cochrane Handbook for Systematic Reviews of Interventions. Version 5.1.0 (updated March 2011). The Cochrane Collaboration. Available from URL: http:// handbook.cochrane.org/ (accessed September 2017).

15. IntHout J, Ioannidis JP, Borm GF. The Hartung-Knapp-SidikJonkman method for random effects meta-analysis is straightforward and considerably outperforms the standard DerSimonian-Laird method. BMC Med Res Methodol 2014; 18: 14-25.

16. Jackson D, Bowden J, Baker R. How does the DerSimonian and Laird procedure for random effects meta-analysis compare with its more efficient but harder to compute counterparts? J Stat Plan Inference 2010; 140: 961-70.

17. Williams BA, Schott NJ, Mangione MP, Ibinson JW. Perineural dexamethasone and multimodal perineural analgesia: how much is too much? Anesth Analg 2014; 118: 912-4.

18. Rahangdale $R$, McCarthy $R J$. In response. Intravenous and perineural dexamethasone in peripheral nerve block: are they truly equivalent? Anesth Analg 2015; 121: 251-2.

19. De Oliveira GS, Jr Almeida MD, Benzon HT, McCarthy RJ. Perioperative single dose systemic dexamethasone for postoperative pain: a meta-analysis of randomized controlled trials. Anesthesiology 2011; 115: 575-88.

20. Jaeger P, Grevstad U, Koscielniak-Nielsen ZJ, Sauter AR, Sorensen JK, Dahl JB. Does dexamethasone have a perineural mechanism of action? A paired, blinded, randomized, controlled study in healthy volunteers. Br J Anaesth 2016; 117: 635-41.

21. Woo JH, Kim YJ, Kim DY, Cho S. Dose-dependency of dexamethasone on the analgesic effect of interscale block for arthroscopic shoulder surgery using ropivacaine $0.5 \%$ : a randomized controlled trial. Eur J Anaesthesiol 2015; 32: 650-5.

22. Aliste J, Leurcharusmee P, Engsusophon $P$, et al. A randomized comparison between intravenous and perineural dexamethasone for ultrasound-guided axillary block. Can J Anesth 2017; 64: 29-36.

23. Dawson RL, McLeod DH, Koerber JP, Plummer JL, Dracopoulos $G C$. A randomised controlled trial of perineural vs intravenous dexamethasone for foot surgery. Anaesthesia 2016; 71: 285-90.

24. Leurcharusmee P, Aliste J, Van Zundert TC, et al. A multicenter randomized comparison between intravenous and perineural dexamethasone for ultrasound-guided infraclavicular block. Reg Anesth Pain Med 2016; 41: 328-33.

25. Morales-Muñoz C, Sánchez-Ramos JL, Díaz-Lara MD, GonzálezGonzález J, Gallego-Alonso I, Hernández-del-Castillo MS. Analgesic effect of a single-dose of perineural dexamethasone on ultrasound-guided femoral nerve block after total knee replacement. Rev Esp Anestesiol Reanim (Spanish). 2017; 64: 19-26.

26. Rahangdale R, Kendall MC, McCarthy RJ, et al. The effects of perineural versus intravenous dexamethasone on sciatic nerve 
blockade outcomes: a randomized, double-blind, placebocontrolled study. Anesth Analg 2014; 118: 1113-9.

27. Rosenfeld DM, Ivancic MG, Hattrup SJ, et al. Perineural versus intravenous dexamethasone as adjuncts to local anaesthetic brachial plexus block for shoulder surgery. Anaesthesia 2016; 71: 380-8.

28. YaDeau JT, Paroli L, Fields $K G$, et al. Addition of dexamethasone and buprenorphine to bupivacaine sciatic nerve block: a randomized controlled trial. Reg Anesth Pain Med 2015; 40: $321-9$

29. Abdelhamid BM, Elshzly I, Badawy S, Yossef A. Efficacy and safety of dexamethasone as an adjuvant to local anesthetics in lumbar plexus block in patients undergoing arthroscopic knee surgeries. J Anesth Clin Res 2016; 7: 601.

30. Sakae TM, Marchioro P, Trevisol FB, Trevisol DJ. Dexamethasone as a ropivacaine adjuvant for ultrasound-guided interscalene brachial plexus block: a randomized, double blinded clinical trial. J Clin Anesth 2017; 38: 133-6.

31. Naim HE, Elshafaie KA, Soaida S, Abdel-Haq MM, Nawar KM. Systemic versus perineural dexamethasone as an adjuvant to bupivacaine in combined femoral and sciatic nerve blocks in lower limb vascular surgeries: a prospective randomized study. Ains Shams Journal of Anesthesiology 2016; 9: 569-75.

32. Albrecht E, Kern C, Kirkham KR. A systematic review and metaanalysis of perineural dexamethasone for peripheral nerve blocks. Anaesthesia 2015; 70: 71-83.

33. Noss C, MacKenzie L, Kostash M. Dexamethasone a promising adjuvant in brachial plexus anesthesia? A systematic review. J Anesth Clin Res 2014; 5: 421.

34. An K, Elkassabany NM, Liu J. Dexamethasone as adjuvant to bupivacaine prolongs the duration of thermal antinociception and prevents bupivacaine-induced rebound hyperalgesia via regional mechanism in a mouse sciatic nerve block model. PloS One 2015; 10: $\mathrm{e} 0123459$.

35. Alarasan A, Agrawal J, Choudhary B, Melhotra A, Uike S, Mukherji A. Effect of dexamethasone in low volume supraclavicular brachial plexus block: a double-blinded randomized clinical study. J Anaesthesiol Clin Pharmacol 2016; 32: 234-9.

36. Jadon A, Dixit S, Kedia S, Chakraborty S, Agrawal A, Sinha N. Interscalene brachial plexus block for shoulder arthroscopic surgery: prospective randomised controlled study of effects of $0.5 \%$ ropivacaine and $0.5 \%$ ropivacaine with dexamethasone. Indian J Anaesth 2015; 59: 171-6.

37. Baloda R, Bhupal JP, Kumar P, Gandhi GS. Supraclavicular brachial plexus block with or without dexamethasone as an adjuvant to $0.5 \%$ levobupivacaine: a comparative study. J Clin Diagn Res 2016; 10: UC09-12.

38. Chong MA, Berbenetz $M$, Lin $C$, Singh S. Perineural versus intravenous dexamethasone as an adjuvant for peripheral nerve blocks: a systematic review and meta-analysis. Reg Anesth Pain Med 2017; 42: 319-26.

39. Zorrilla-Vaca A, Li J. Dexamethasone injected perinerually is more effective than administered intravenously for peripheral nerve blocks: A meta-analysis of randomized controlled trials. Clin J Pain 2017. https://doi.org/10.1097/AJP.0000000000000519.

40. Friedrich JO, Adhikari NK, Beyene J. The ratio of means method as an alternative to mean differences for analyzing continuous outcome variables in meta-analysis: a simulation study. BMC Med Res Methodol 2008; 8: 32.

41. Friedrich JO, Adhikari NK, Beyene J. Ratio of means for analyzing continuous outcomes in meta-analysis performed as well as mean difference methods. J Clin Epidemiol 2011; 64: 556-64.

42. Dexter F, Bayman EO, Epstein RH. Statistical modeling of average and variability of time to extubation for meta-analysis comparing desflurane to sevoflurane. Anesth Analg 2010; 110: 570-80.

43. Wachtel RE, Dexter F, Epstein RH, Ledolter J. Meta-analysis of desflurane and propofol average times and variability in times to extubation and following commands. Can J Anesth 2011; 58: 714-24.

44. Williams BA, Hough KA, Tsui BY, Ibinson JW, Gold MS, Gebhart $G F$. Neurotoxicity of adjuvants used in perineural anesthesia and analgesia in comparison with ropivacaine. Reg Anesth Pain Med 2011; 36: 225-30.

45. Williams BA, Butt MT, Zeller JR, Coffee S, Pippi MA. Multimodal perineural analgesia with combined bupivacaine-clonidinebuprenorphine-dexamethasone: safe in vivo and chemically compatible in solution. Pain Medicine 2015; 16: 186-98. 